\title{
COMPARAÇÁO ENTRE O MÉTODO DIRETO E INDIRETO NA PROPAGAÇĀO DE PULSO ULTRASSÔNICO EM PAINÉIS DE ALVENARIA
}

\author{
SOUSA, ISRAEL \\ Estudante de graduação \\ UFC - Russas/ LAREB \\ Ceará; Brasil \\ israelnlsousa@gmail.com \\ RODRIGUES, TALISON \\ Estudante de graduação \\ UFC - Russas/ LAREB \\ Ceará; Brasil \\ talisonmec@hotmail.com
}

\author{
ARAUJO, EMANUEL \\ Estudante de graduação \\ UFC - Russas/ LAREB \\ Ceará; Brasil \\ emanuhenriqcivil@gmail.com \\ MESQUITA, ESEQUIEL \\ Professor, $\mathrm{PhD}$ \\ UFC - Russas/ LAREB \\ Ceará; Brasil \\ emesquita@ufc.br
}

\section{RESUMO}

A utilização de ensaios não destrutivos na caracterização de materiais ou de construções tem ganhado espaço em função da necessidade de estudos acerca do patrimônio histórico. Dessa forma, o ensaio ultrassônico surge como alternativa eficaz na análise do seu desempenho. No entanto, os diferentes métodos de análise, direto, indireto e semidireto apresentam resultados diferentes na obtenção das velocidades de pulso ultrassônico (VPU). Em função disso, foram realizadas comparações entre alguns desses métodos, buscando traçar comportamento semelhante entre os resultados obtidos por eles. Para isso, foram realizadas medições pelos métodos direto e indireto, em um painel de alvenaria de $150 \times 100 \times 13.5 \mathrm{~cm}$, por meio do equipamento Proceq ${ }^{\circledR}$ PUNDIT $2000^{\circledR} 54 \mathrm{KHz}$. Ao comparar os resultados em ambos os métodos, foi possível estabelecer uma correlação de semelhança entre eles, permitindo compreender acerca das suas aplicações e interpretação de seus dados.

Palavras-chave: velocidade de pulso ultrassônico, método indireto, painéis de alvenaria.

\section{ABSTRACT}

The use of non-destructive tests to characterize materials or constructions has gained ground due to the need for studies on historical heritage. Thus, the ultrasonic test appears as an effective alternative in the analysis of its performance. However, the different methods of analysis, direct, indirect and semi-direct present different results in obtaining ultrasonic pulse velocities (UPV). As a result, comparisons were made between some of these methods, seeking to trace similar behavior among the results obtained by them. For this, measurements were performed by direct and indirect methods on a $150 \times 100 \times 13.5 \mathrm{~cm}$ masonry panel using the Proceq ${ }^{\circledR}$ PUNDIT $2000 ® 54 \mathrm{KHz}$ equipment. By comparing the results in both methods, it was possible to establish a similarity correlation between them, allowing to understand about its application and interpretation of its data.

Keywords: ultrasonic pulse velocity, indirect method, masonry panels.

\section{INTRODUÇÃO}

O desenvolvimento de técnicas não destrutivas tem ganhado espaço nos últimos anos, em função principalmente do estudo crescente acerca do patrimônio histórico, com a necessidade de compreender as características dos elementos estruturais e dos materiais causando pouco ou nenhum dano à estrutura. Dessa forma destacam-se alguns ensaios não destrutivos, dentre eles os ensaios sônicos e os sistemas de monitoramento (MESQUITA et al., 2016; RAMOS et al., 2010).

A aplicação dessas técnicas tem se tornado objeto de estudo pelo mundo, o que possibilita o desenvolvimento adequado da sua utilização. Os ensaios ultrassônicos, em especial, possuem uma extensa possibilidade de aplicações, questão ainda em estudo, como pesquisas atuais que buscam utilizar esse método para ampliar a investigação acerca do patrimônio histórico.

O conhecimento acerca dos materiais utilizados nas construções ainda é objeto de estudo, dessa forma, torna-se fundamental na compreensão do edificado histórico, como mostrado por (SILVEIRA; VARUM; COSTA, 2013) e (SILVEIRA et al., 2012), em que foram realizados estudos buscando compreender as diferentes propriedades mecânicas 
dos tijolos de adobe de Aveiro, contribuindo na caracterização desse material e permitindo a obtenção de parâmetros de referência que pudessem ser utilizados em eventuais reabilitações.

Essa dificuldade de análise das características construtivas e de materiais permitiu, portanto, o desenvolvimento de técnicas não destrutivas, na caracterização dos materiais componentes das construções históricas, como o ensaio ultrassônico, responsável pela obtenção de propriedades como a velocidade de pulso ultrassônico, meio pelo qual torna possível a identificação de características como a resistência à compressão e o módulo de elasticidade do concreto. No entanto, mesmo com a implementação dessa técnica, ainda existem dificuldades na caracterização de alguns materiais, como as alvenarias de argila, de pedra (NOOR-E-KHUDA; ALBERMANI, 2019), (KOROTH; FAZIO; FELDMAN, 1998), (ALIABDO; ELMOATY, 2012), e argamassas (WICIAK; CASCANTE; POLAK, 2017).

Os ensaios ultrassônicos têm se difundido, portanto, como alternativa na compreensão dessas propriedades, como em (MESQUITA et al., 2018), onde foram analisadas as características dos painéis de alvenaria da Igreja Nossa Senhora do Rosário dos Pretos, por meio do método indireto do ensaio ultrassônico, permitindo identificar a presença de vazios na composição da alvenaria e revestimento, bem como identificar a presença de fissuras.

O ensaio ultrassônico, portanto, consiste na utilização de dois transdutores, materiais piezoelétricos, que convertem o pulso elétrico emitido, em uma onda mecânica de frequência superior a $20 \mathrm{KHz}$, propagada pelo transdutor transmissor e recebida pelo transdutor receptor, que permite a conversão da onda mecânica recebida novamente em um pulso elétrico, que pode ser traduzida para o visor na forma de tempo e velocidade de propagação da onda. Portanto, o percurso percorrido pela onda permite a compreensão das características dos materiais em análise.

No ensaio ultrassônico, existem três métodos que possibilitam a medição adequada das velocidades de pulso ultrassônicas, são o método direto, indireto e semi-direto. O método direto constitui-se como a principal alternativa na realização do ensaio, uma vez que consiste no posicionamento dos transdutores em faces opostas, possibilitando que a onda percorra a maior extensão do objeto em análise, permitindo medidas mais seguras. O método indireto consiste na realização da medição ao longo de uma única face, compreendendo a variação da posição dos transdutores ao longo da extensão da face em análise. Já o método semi-direto, consiste na realização do procedimento com os transdutores posicionados em faces ortogonais, indicando o caminho seguido pela onda nessa medição.

A aplicação do método indireto ocorre principalmente em função da dificuldade de utilização do método direto, fato compreendido principalmente na mensuração das velocidades ultrassônicas em paredes, uma vez que a limitação do tamanho dos cabos que conectam os transdutores impossibilita a adequada realização do procedimento. Desse modo, o método indireto surge como alternativa eficaz, graças a possibilidade de realização da mensuração ao longo de um único sentido, permitindo aferir as propriedades de paredes de grandes extensões.

Portanto, o presente trabalho busca comparar os métodos direto e indireto, objetivando assegurar uma boa correlação entre essas metodologias de análise, bem como contribuir na compreensão acerca da realização desses procedimentos, contribuindo no desenvolvimento dos ensaios não destrutivos para a determinação de características de alvenarias.

\section{PRINCÍPIOS DAS ONDAS MECÂNICAS}

A onda ultrassônica se configura como uma onda mecânica, com frequência igual ou superior a $20 \mathrm{KHz}$ e difere-se da onda eletromagnética, principalmente pela capacidade de não poder se propagar no vácuo e necessitar, portanto, de um meio material para sua propagação. Dessa forma, as ondas mecânicas são divididas em ondas de corpo e ondas de superfícies, em que a principal diferença está relacionada ao sentido de propagação da onda.

Essencialmente, as ondas de corpo são divididas em ondas longitudinais e transversais, as primeiras são também conhecidas como ondas de compressão, pois se propagam em direção longitudinal, paralelas a direção de propagação da onda, e apresentam-se como as ondas mais rápidas dentre as ondas mecânicas. A segunda é propagada no sentido perpendicular em relação a direção de propagação da onda, sendo ocasionadas geralmente por movimentos vibratórios.

Dentre as ondas superficiais destaca-se as ondas de Rayleigh, que apresentam comportamento semelhante a onda do mar, propagando-se ao longo da superfície e também seguindo as camadas subjacentes, no entanto, a medida em que a onda penetra o material, o efeito dessa onda é reduzido drasticamente (MIRANDA, 2011). 
Portanto, na realização do ensaio pelo método direto, predomina-se a captação de ondas de corpo, essencialmente as ondas longitudinais e transversais, caracterizadas por uma maior velocidade em relação as demais ondas mecânicas, enquanto na realização do método indireto, predomina-se as ondas de superfície, principalmente as ondas de Rayleigh, presentes com menor velocidade.

\section{METODOLOGIA}

Para a realização do ensaio de ultrassom, foi utilizado o equipamento Proceq ${ }^{\circledR}$ PUNDIT $2000^{\circledR} 54$ KHz, acoplado a dois transdutores, transmissor e receptor, permitindo a mensuração das velocidades de pulso ultrassônico. Para isso, foi então construído um painel de 150 × $100 \times 13.5 \mathrm{~cm}$, com tijolos de dimensões 24.7 × 12.3 × $4.6 \mathrm{~cm}$, bem como uma argamassa de assentamento com o traço 1:5, objetivando viabilizar a aplicação do ensaio ultrassônico. O painel construído ainda apresentou uma das faces revestidas completamente com argamassa de cal, com o traço 1:6, evidenciada na Figura 1 (b), enquanto na outra face os tijolos permaneceram aparentes, como mostra a Figura 1 (a).

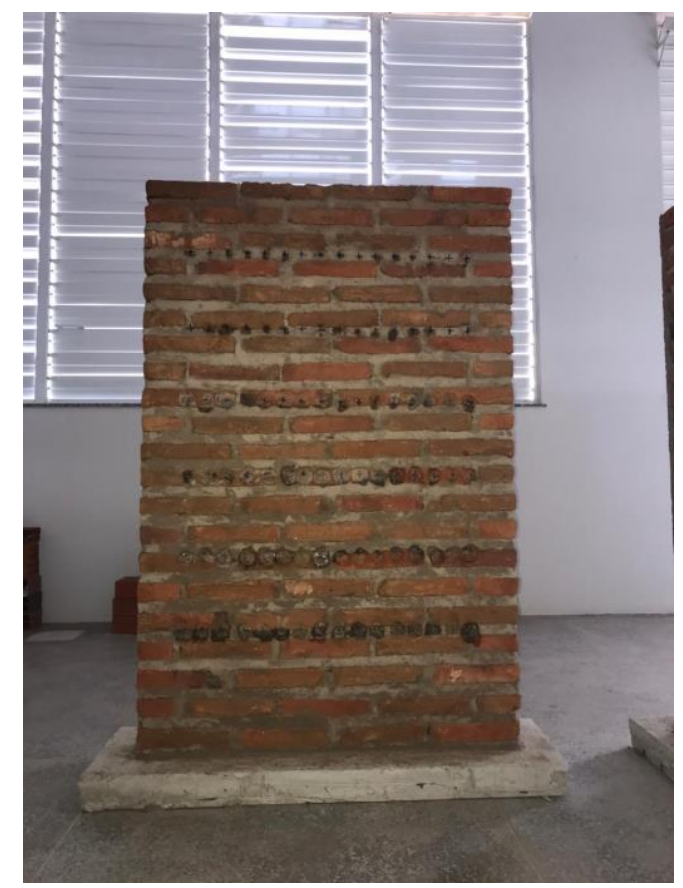

(a)

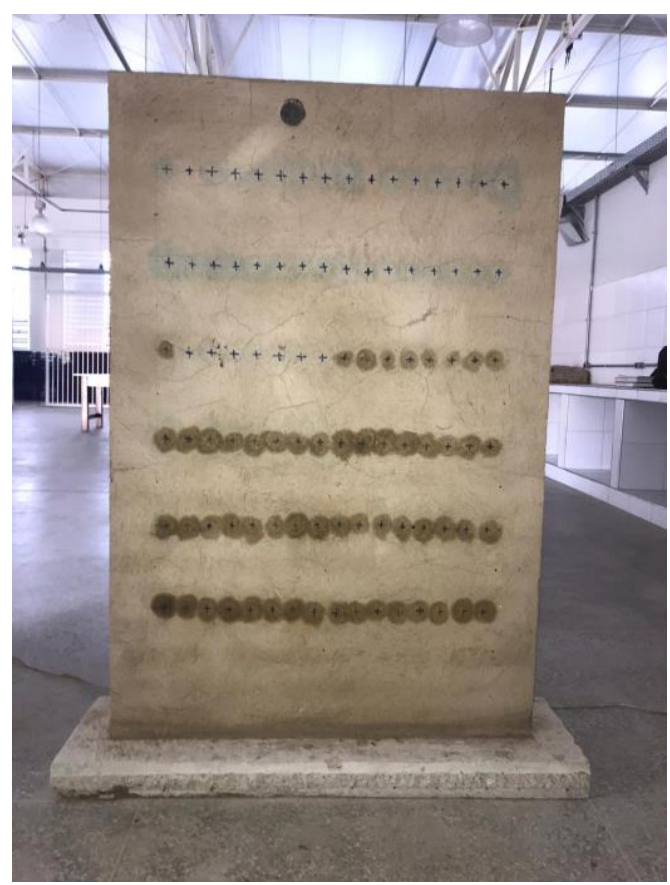

(b)

Figura 1: Painel de alvenaria: a) sem revestimento; b) com revestimento

A utilização do método indireto para a realização do ensaio foi efetuada na face com revestimento, principalmente devido a maior praticidade na realização do procedimento, uma vez que apresentava a região mais regular que a face sem revestimento, permitindo uma melhor acoplagem dos transdutores ao painel.

Para a aplicação do método, foram selecionados 12 quadrantes de 40 x $20 \mathrm{~cm}$ no painel em estudo, espaçados $20 \mathrm{~cm}$ da base e $10 \mathrm{~cm}$ das demais extremidades, como mostra a Figura 2. Dessa forma para a aplicação do método direto, foram realizadas 8 medições posicionando-se os transdutores em cada um dos quadrantes e variando sua posição em $5 \mathrm{~cm}$. No entanto, para a implementação do método indireto, seguiu-se as determinações de (MESQUITA et al., 2018), em que inicialmente o transdutor transmissor foi espaçado em $10 \mathrm{~cm}$ do transdutor receptor, e posteriormente variou-se a posição do segundo em 5 cm até a obtenção de 6 medições. 


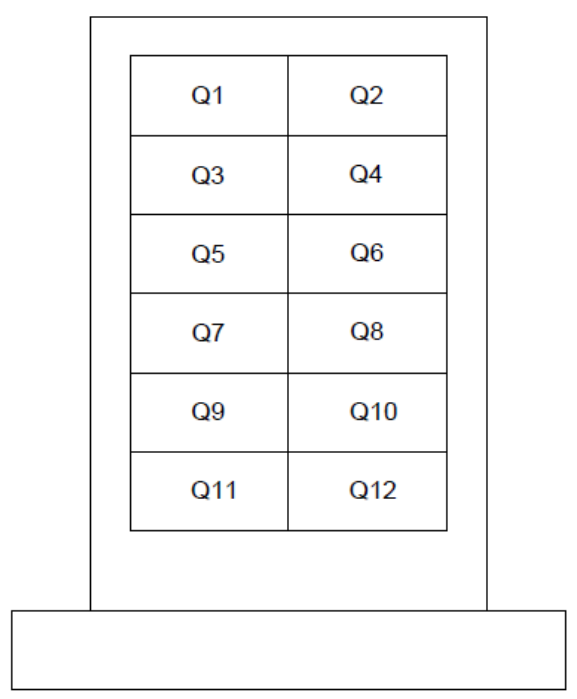

Figura 2: Modelo mostrando as subdivisões dos quadrantes no painel em estudo

Buscando padronizar as medidas da análise, foi então realizada a média aritmética das medições ao longo de todos os 12 quadrantes, permitindo caracteriza-los quanto aos valores de velocidade de pulso ultrassônico (VPU). Os resultados encontrados das VPU's foram processados pelo software SURFER®, permitindo a montagem do mapa de cores, de modo a contribuir na visualização das alterações das velocidades no painel.

\section{RESULTADOS}

$\mathrm{Na}$ face do painel com revestimento, foi observada pelo método indireto, que os valores das VPU's se apresentaram na faixa de $722 \mathrm{~m} / \mathrm{s}$ a $1755 \mathrm{~m} / \mathrm{s}$, ao passo que os valores encontrados referentes ao método direto estiveram compreendidos na faixa de $2468 \mathrm{~m} / \mathrm{s}$ a $3881 \mathrm{~m} / \mathrm{s}$. Dessa forma, foram comparados os valores dessas velocidades em relação a cada um dos quadrantes (Tabela 1).

Tabela 1 - Valores das VPU's (m/s) por quadrante e a relação entre os métodos direto e indireto

\begin{tabular}{cccc}
\hline & Método direto & Método indireto & Relação entre os métodos (\%) \\
\hline \hline Q1 & 3482 & 722 & 20.735 \\
Q2 & 2963 & 1053 & 35.538 \\
Q3 & 3047 & 1124 & 36.889 \\
Q4 & 3302 & 1421 & 43.035 \\
Q5 & 2493 & 1755 & 70.397 \\
Q6 & 2468 & 812 & 32.901 \\
Q7 & 2553 & 951 & 37.250 \\
Q8 & 2718 & 1565 & 57.579 \\
Q9 & 3251 & 1143 & 35.158 \\
Q10 & 3248 & 1528 & 47.044 \\
Q11 & 3881 & 1598 & 41.175 \\
Q12 & 3829 & 1149 & 30.008 \\
\hline
\end{tabular}

Por meio dos ensaios ultrassônicos, foi possível identificar que, para o quadrante 1, a utilização do método direto promoveu valores altos de velocidade de pulso ultrassônico, equivalente a $3482 \mathrm{~m} / \mathrm{s}$, enquanto que para o mesmo quadrante, seguindo determinações do método indireto, foi encontrado valor de VPU equivalente a $722 \mathrm{~m} / \mathrm{s}$, indicando um valor equivalente a cerca de $20.73 \%$ em relação ao encontrado no método direto e correspondendo, dessa forma, à maior diferença entre os valores de VPU's encontrados em ambos os métodos.

Para o quadrante 2, foram observados valores de VPU equivalentes a $2986 \mathrm{~m} / \mathrm{s}$ pelo método direto e $1053 \mathrm{~m} / \mathrm{s}$ pelo 
método indireto, equivalente a uma variação de $35.54 \%$ do valor encontrado pelo método direto. Já para o quadrante 3 , foi encontrado o valor de VPU equivalente a $3047 \mathrm{~m} / \mathrm{s}$ pelo método direto e $1124 \mathrm{~m} / \mathrm{s}$ pelo método indireto, com uma variação equivalente a $36.89 \%$ deste em relação ao método direto.

Com respeito ao quadrante 4, foi encontrado um valor de VPU equivalente a $3302 \mathrm{~m} / \mathrm{s}$ pelo método direto e $1421 \mathrm{~m} / \mathrm{s}$ pelo método indireto, justificando uma variação de $43.03 \%$ desse em relação ao valor encontrado pelo método direto. $\mathrm{O}$ quadrante 5 apresentou valores de VPU equivalente a $2493 \mathrm{~m} / \mathrm{s}$, pelo método direto, enquanto que pelo método indireto, o valor encontrado foi equivalente a $1755 \mathrm{~m} / \mathrm{s}$, justificando uma relação de $70.39 \%$ em relação ao método direto e por consequência, o valor encontrado nesse quadrante apresentou a menor diferença entre valores de VPU's em ambos os métodos.

O quadrante 6 apresentou, pelo método direto, um valor de VPU equivalente a $2468 \mathrm{~m} / \mathrm{s}$, enquanto que pelo método indireto, o valor correspondeu a $812 \mathrm{~m} / \mathrm{s}$, justificando uma relação de $32.90 \%$ do valor da velocidade encontrada pelo método indireto, em relação ao valor obtido pelo método direto. Da mesma forma, o quadrante 7 apresentou valores médios de VPU equivalentes a $2553 \mathrm{~m} / \mathrm{s}$ pelo método direto, ao passo que pelo método indireto, apresentou valor médio equivalente a $951 \mathrm{~m} / \mathrm{s}$, com uma relação $37.25 \%$ em relação ao método direto.

Se tratando do quadrante 8 , os valores de VPU's encontrados foram equivalentes a $2718 \mathrm{~m} / \mathrm{s}$ pelo método direto, enquanto que pelo método indireto o valor correspondeu a $1565 \mathrm{~m} / \mathrm{s}$, indicando uma relação de $57.58 \%$ com o valor da velocidade encontrada pelo método direto. Com respeito ao quadrante 9, foi observado valores de VPU's equivalentes a $3251 \mathrm{~m} / \mathrm{s}$ pelo método direto, ao passo que para o método indireto, foi observado valor equivalente a $1143 \mathrm{~m} / \mathrm{s}$, justificando uma relação de $35.16 \%$ do valor encontrado pelo método indireto em relação ao método direto.

O quadrante 10, por sua vez, apresentou valores de velocidades equivalentes a $3248 \mathrm{~m} / \mathrm{s}$ pelo método direto, enquanto que pelo método indireto, apresentou valores equivalentes a $1528 \mathrm{~m} / \mathrm{s}$, justificando uma relação entre eles de $47.04 \%$. Os quadrantes 11 e 12 apresentaram respectivamente $3881 \mathrm{~m} / \mathrm{s}$ e $3829 \mathrm{~m} / \mathrm{s}$, com respeito a VPU obtida pelo método direto, enquanto que pelo método indireto, os valores encontrados foram equivalentes a $1598 \mathrm{~m} / \mathrm{s}$ e $1149 \mathrm{~m} / \mathrm{s}$, justificando relações entre os valores das velocidades em cada quadrante iguais a $41.17 \%$ e $30.01 \%$.

Dessa forma, a média das relações em ambos os métodos apresentou valor equivalente a 40.64\%, com um desvio padrão igual a $13.04 \%$.

O comportamento das velocidades no painel e em cada um dos quadrantes, pode ser observado na Figura 3.

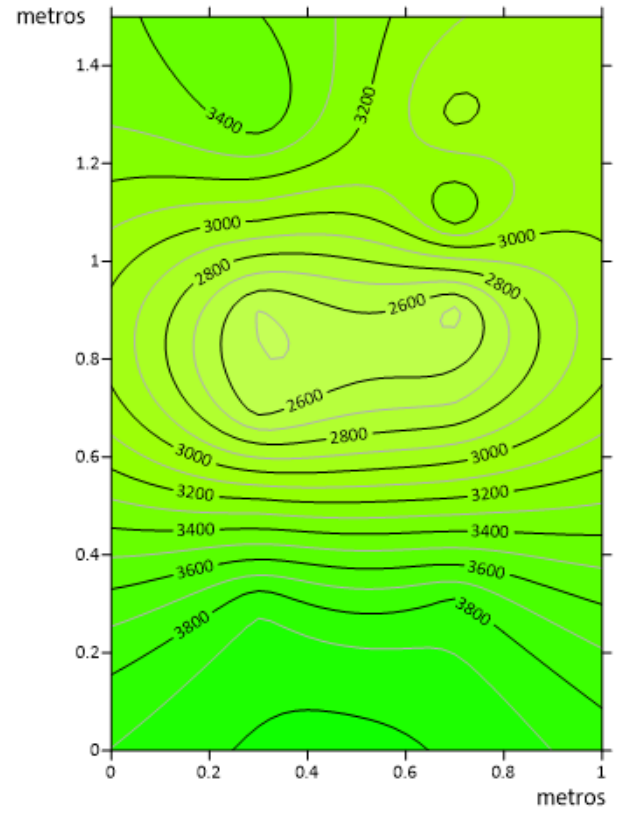

(a)

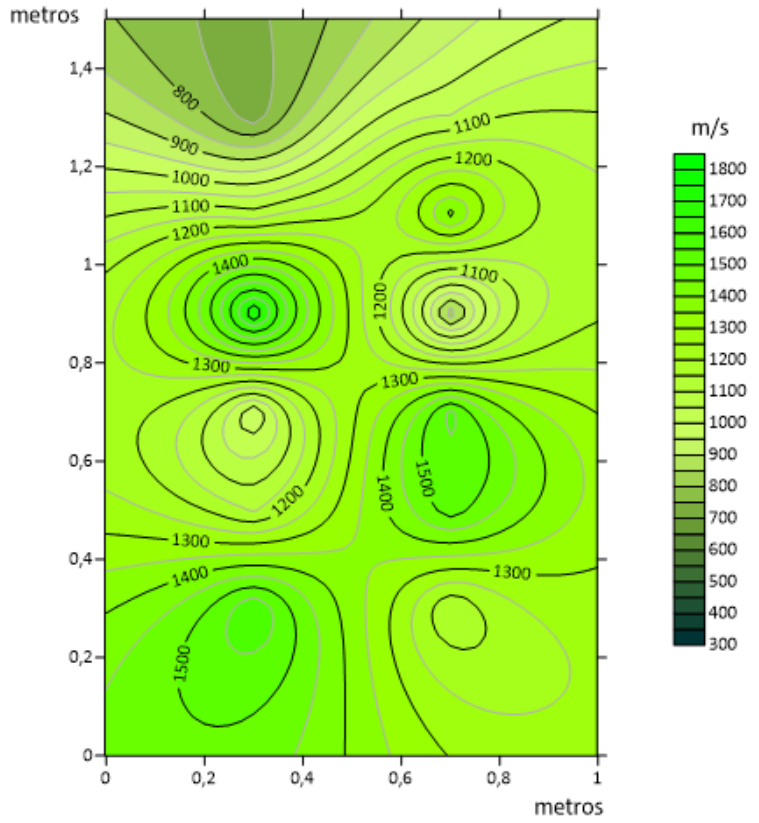

(b)

Figura 3: Mapa de cores das VPU's encontradas pelo: a) método direto; b) método indireto 
Foi possível observar, pelo método direto, valores de velocidade de pulso ultrassônico menores na região central do painel utilizada na análise, compreendida nos quadrantes 5, 6, 7 e 8, bem como uma região uniforme compreendida nos quadrantes $9,10,11$ e 12 .

Já pelo método indireto, foi perceptível o comportamento homogêneo da velocidade de pulso ultrassônico, principalmente nos quadrantes $3,4,5,6,7,8,9,10,11$ e 12 . Já que no quadrante 1 foi observado o menor valor médio da VPU pelo método indireto.

\section{CONCLUSÕES}

O presente trabalho buscou realizar um comparativo entre os valores obtidos das velocidades de pulso ultrassônico por meio do método direto e indireto em painéis de alvenaria, buscando contribuir também acerca da compreensão das velocidades das ondas encontrada em diferentes materiais.

A maior proximidade entre as velocidades de pulso ultrassônico de ambos os métodos foi encontrada no quadrante 5, em que correspondeu pelo método direto à $2493 \mathrm{~m} / \mathrm{s}$, enquanto que pelo método indireto o valor obtido foi de $1755 \mathrm{~m} / \mathrm{s}$. Já a maior diferença entre VPU's observada em um único quadrante, ocorreu no quadrante 1, em que pelo método direto o valor correspondeu a $3482 \mathrm{~m} / \mathrm{s}$, enquanto que pelo método indireto, obteve-se $722 \mathrm{~m} / \mathrm{s}$.

Portanto, foi possível identificar uma variação média de $40.64 \%$ nos valores médios das velocidades de pulso ultrassônico de cada quadrante pelo método indireto em relação ao método direto. Explicada principalmente pela predominância de ondas de Rayleigh a serem captadas pelo transdutor receptor no método indireto.

Dessa forma, ambos os métodos apresentam resultados adequados para análise, no entanto, o comportamento diferente de ambos pode ser relacionado ao comportamento da onda nos diferentes materiais.

Assim, as diferenças das velocidades encontradas principalmente nos quadrantes 5, 6, 7 e 8, pelo método direto, podem estar associadas principalmente a qualidade do material utilizado, podendo indicar a presença de vazios que contribuem na redução da velocidade de propagação da onda. Bem como as diferenças das velocidades encontradas no método indireto, como a velocidade de $722 \mathrm{~m} / \mathrm{s}$ observada no quadrante 1, que está relacionada à passagem da onda apenas no revestimento de cal, reduzindo a velocidade de propagação da onda nessa região.

Foram observados também nos quadrantes 11 e 12, valores de VPU's equivalentes à $3881 \mathrm{~m} / \mathrm{s}$ e 3829 m/s pelo método direto, ambos se referem a passagem da onda majoritariamente pela argamassa de assentamento, indicada pelas altas velocidades.

Os mapas de cores evidenciam as diferenças das velocidades em cada um dos quadrantes do painel em estudo, permitindo identificar com maior facilidade os valores reduzidos das VPU's no centro do painel onde se realizou a medição pelo método direto. Através do método indireto também ficou evidente a homogeneidade das VPU's, dada a baixa variação em relação ao método direto, dessa forma, apenas os quadrantes iniciais apresentaram valores com comportamento diferente das demais, com os módulos das velocidades mais baixos encontrados na realização do procedimento experimental.

Finalmente, a análise dos métodos direto e indireto no trabalho, permitem contribuir com o conhecimento acerca da interpretação dos dados obtidos nas diferentes metodologias de ensaio, contribuindo na compreensão acerca da influência de diferentes materiais nos valores das velocidades de pulso ultrassônico.

\section{REFERÊNCIAS}

ALIABDO, A. A. E.; ELMOATY, A. E. M. A. Reliability of using nondestructive tests to estimate compressive strength of building stones and bricks. Alexandria Engineering Journal, v. 51, n. 3, p. 193-203, 2012.

KOROTH, B. S. R.; FAZIO, P.; FELDMAN, D. Evaluation of Clay Brick Durability Using Ultrasonic Pulse Velocity. v. 4, n. 2, p. 142-147, 1998.

MESQUITA, E. et al. Global overview on advances in structural health monitoring platforms. Journal of Civil 
Structural Health Monitoring, v. 6, n. 3, p. 461-475, 2016.

MESQUITA, E. et al. Non-destructive characterization of ancient clay brick walls by indirect ultrasonic measurements. Journal of Building Engineering, v. 19, n. January, p. 172-180, 2018.

MIRANDA, L. Ensaios acústicos e de macacos planos em alvenarias resistentes. [s.1.] Universidade do Porto, 2011.

NOOR-E-KHUDA, S.; ALBERMANI, F. Mechanical properties of clay masonry units: Destructive and ultrasonic testing. Construction and Building Materials, v. 219, p. 111-120, 20 set. 2019.

RAMOS, L. F. et al. Monitoring historical masonry structures with operational modal analysis: Two case studies. Mechanical Systems and Signal Processing, v. 24, n. 5, p. 1291-1305, 2010.

SILVEIRA, D. et al. Mechanical properties of adobe bricks in ancient constructions. Construction and Building Materials, v. 28, n. 1, p. 36-44, 2012.

SILVEIRA, D.; VARUM, H.; COSTA, A. Influence of the testing procedures in the mechanical characterization of adobe bricks. Construction and Building Materials, v. 40, p. 719-728, 2013.

WICIAK, P.; CASCANTE, G.; POLAK, M. A. Sensor and Dimensions Effects in Ultrasonic Pulse Velocity Measurements in Mortar Specimens. Procedia Engineering, v. 193, p. 409-416, 1 jan. 2017. 